Document downloaded from:

http://hdl.handle.net/10251/87830

This paper must be cited as:

Mitsuuchi Tashima, M.; Soriano Martinez, L.; Paya Bernabeu, JJ.; Monzó Balbuena, JM.; Borrachero Rosado, MV. (2016). Assesssment of pozzolanic/hydraulic reactivity of vitreous calcium aluminosilicate (VCAS) ussing different methods. Materials and Design. 96:424-430. doi:10.1016/j.matdes.2016.02.036.

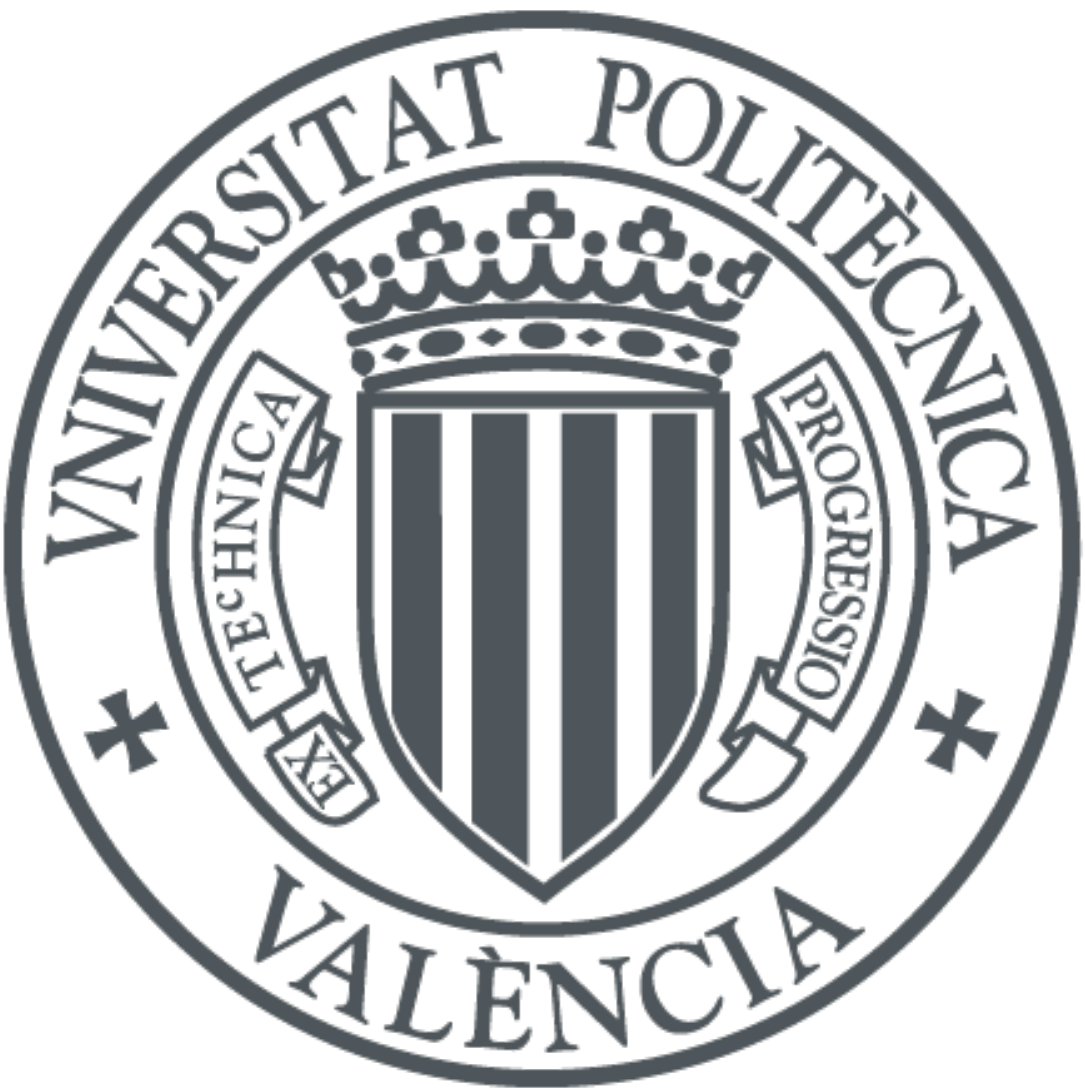

The final publication is available at

http://dx.doi.org/10.1016/j.matdes.2016.02.036

Copyright Elsevier

Additional Information 


\title{
Assessment of pozzolanic/hydraulic reactivity of vitreous calcium aluminosilicate (VCAS)
}

\author{
M.M. Tashima ${ }^{1 *}$, L. Soriano ${ }^{2}$, J. Payá ${ }^{2}, J_{.}$Monzó $^{2}$, M.V. \\ Borrachero $^{2}$
}

maumitta@hotmail.com, lousomar@upvnet.upv.es,jjpaya@cst.upv.es,jmmonzo@cst.upv.es, vborrachero@cst.upv.es

${ }^{1}$ UNESP - Univ Estadual Paulista, Campus de Ilha Solteira. Alameda Bahia, 550. CEP:15385-000 Ilha Solteira-SP, Brazil.

${ }^{2}$ Instituto de Ciencia y Tecnología del Hormigón. Universitat Politècnica de València. Camino de Vera s/n, Edificio 4G, 46022 Valencia. Spain.

*Corresponding author: maumitta@hotmail.com, phone +55 1837431217.

\begin{abstract}
The aim of this paper is to assess the possibility of using vitreous calcium aluminosilicate (VCAS) as a supplementary cementitious material in the production of Portland cement mortars. The calcium hydroxide consumption by VCAS is assessed by two different methods: firstly, a classical method based on thermogravimetric analysis (TGA) and, secondly, $\mathrm{pH}$ and electrical conductivity measurements of calcium hydroxide/VCAS suspensions with excess calcium hydroxide. Evidence of pozzolanic reactivity of VCAS is revealed in hydrated lime pastes, and low reactivity was observed in aqueous suspensions. The reactivity of VCAS is also assessed by means of TGA of VCAS/OPC pastes and by means of the mechanical strength development of Portland cement mortars, with VCAS replacement percentages in the range of $10-30 \%$. The results obtained show that pozzolanic and hydraulic reactions take place in OPC systems. VCAS can be used as a supplementary cementitious material by replacing OPC at levels of 10$30 \%$ by mass.
\end{abstract}

Keywords: VCAS, pozzolanic reactivity, hydraulic reactivity, thermogravimetric analysis, $\mathrm{pH}$ and electrical conductivity measurements, compressive strength. 


\section{Introduction}

The use of supplementary cementitious materials (SCMs) in the construction industry is an environmentally friendly practice that has been extended in the last decades. Such materials can enhance the mechanical strength and durability aspects of mortars and concretes. In most cases, SCMs are mainly industrial and agroindustrial waste materials that, besides technical benefits for concrete, also present environmental and economic advantages.

It is well known that the production of Portland cement clinker is an industrial activity that requires high energy consumption and huge amounts of raw materials. In addition, this activity is very contaminating: the production of 1 ton of ordinary Portland cement with 95\% of clinker (OPC) is associated with the emission of approximately 0.8 tonne of $\mathrm{CO}_{2}$ to the atmosphere [1]. Hence, the use of SCMs to replace OPC in percentages of $5-40 \%$ can significantly reduce the $\mathrm{CO}_{2}$ emissions associated with Portland cement production and, depending on its reactivity, a high degree of valorization can be associated with a waste material [2].

SCMs are inorganic materials that, when finely divided, can be added to Portland cement mortars and/or concretes, enhancing their mechanical and durability properties [3]. The most widely employed SCMs are fly ash, silica fume, blast furnace slag and metakaolin [4-6]. Some SCMs (e.g. fly ash, silica fume) present pozzolanic activity due to the reaction of amorphous silica and alumina towards calcium hydroxide: these are known as pozzolans; and some SCMs present hydraulic behaviour (e.g. blast furnace slag) because of the presence of anhydrous calcium silicate compounds that hydrate in an alkaline environment. Otherwise, several industrial/agroindustrial wastes such as rice husk ash [7], ceramic wastes [8], fluid catalytic cracking catalyst residue [9] and sugarcane bagasse ash [10-12] have also been investigated for this purpose.

During the production of glass fibre, a waste material is generated: glass fibre waste. After a fusion process of this waste (with the addition of selected quantities of different chemicals), a vitreous calcium aluminosilicate (VCAS) material is obtained. According to Hemmings et al. [13], the glass fibre industry generates about 200,000 tons of waste per year. VCAS is a waste material based on the ternary system 
$\mathrm{CaO}-\mathrm{Al}_{2} \mathrm{O}_{3}-\mathrm{SiO}_{2}$ and its use as SCM for concrete and mortars was patented in 2004 by Hemmings et al. [13].

Since then, only a few references related to the use of this material in blended mortars and concretes can be found. The first reference was published in 2008 [14], where the authors assessed VCAS blended concretes in fresh and hardened states. The main conclusion of the authors was that VCAS improved the workability of the concrete. In 2009, Neithalath et al. [15] compared the use of VCAS and silica fume, showing that VCAS starts to react with calcium hydroxide only after 7 days curing time, while silica fume reacts from the first days of curing.

Another application for VCAS was proposed by Tashima et al. [16], where VCAS was used as raw material in the production of alkali-activated binders. On this subject, the authors have so far published three papers related to a new field for the application of VCAS, obtaining very interesting results [16-18].

Due to the lack of references related to the use of VCAS as a pozzolanic material, the aim of this paper is to assess in depth its reactivity using different experimental techniques. The pozzolanic reactivity of VCAS is evaluated using both calcium hydroxide/VCAS and Portland cement/VCAS systems. The fixed portlandite was assessed using thermogravimetric analysis (TGA) for pastes of calcium hydroxide/VCAS and Portland cement/VCAS pastes. A new method proposed by Tashima et al. [19] to assess the pozzolanic reactivity by means of $\mathrm{pH}$ and electrical conductivity measurements of hydrated lime:pozzolan suspensions is used to compare the obtained data to the thermogravimetric analysis results. Finally, the compressive strength of Portland cement mortars with different percentages of VCAS (10, 20 and 30\%) replacing OPC is assessed for mortars cured for 28 days at room temperature and, the porosity of selected samples is performed using the mercury intrusion porosimetry (MIP) technique.

\section{Experimental}

\subsection{Materials}

Calcium hydroxide (purity of 95\%) supplied by Panreac S.A. was used in the preparation of both calcium hydroxide/VCAS pastes and hydrated lime:VCAS suspensions. Ordinary Portland cement (OPC) type I CEM 52.5R from Lafarge (Puerto de Sagunto, Spain) was used both for thermogravimetric analysis of the 
Portland cement/VCAS pastes and in the production of mortars. In addition, a siliceous sand with a fineness modulus of 4.1 and specific gravity of $2680 \mathrm{~kg} / \mathrm{m}^{3}$ was used in the production of VCAS blended mortars (binder:sand ratio of 1:3 and water:binder ratio of 0.5 , the binder being the sum of the OPC and VCAS). The vitreous calcium aluminosilicate (VCAS), supplied by Vitrominerals, presented a mean particle diameter of about $12 \mu \mathrm{m}$, and an irregular shape morphology with a dense-compact structure [16]. Table 1 shows the chemical composition for both OPC and VCAS, determined by X-ray fluorescence (XRF).

Table 1. Chemical composition of VCAS and OPC (wt\%).

\begin{tabular}{cccccccccc}
\hline & $\mathrm{SiO}_{2}$ & $\mathrm{Al}_{2} \mathrm{O}_{3}$ & $\mathrm{CaO}$ & $\mathrm{Na}_{2} \mathrm{O}$ & $\mathrm{MgO}$ & $\mathrm{K}_{2} \mathrm{O}$ & $\mathrm{Fe}_{2} \mathrm{O}_{3}$ & others & LOI \\
\hline VCAS & 57.90 & 12.92 & 23.51 & 0.74 & 2.88 & 0.13 & 0.47 & 1.20 & 0.25 \\
OPC & 20.80 & 4.60 & 65.60 & 0.07 & 1.20 & 1.00 & 4.80 & - & 2.02 \\
\hline
\end{tabular}

The X-ray diffraction pattern of VCAS, determined using a Philips PW1710 diffractometer with Cu-Ko wavelength and $40 \mathrm{kV}$ and $20 \mathrm{~mA}$, is depicted in Figure 1 . The deviation on the baseline in the range $2 \theta=$ 15-30 can be assigned to its amorphous phase content. A small presence of quartz (PDFcard \#461045) as impurity is detected in the X-ray diffraction pattern of VCAS.

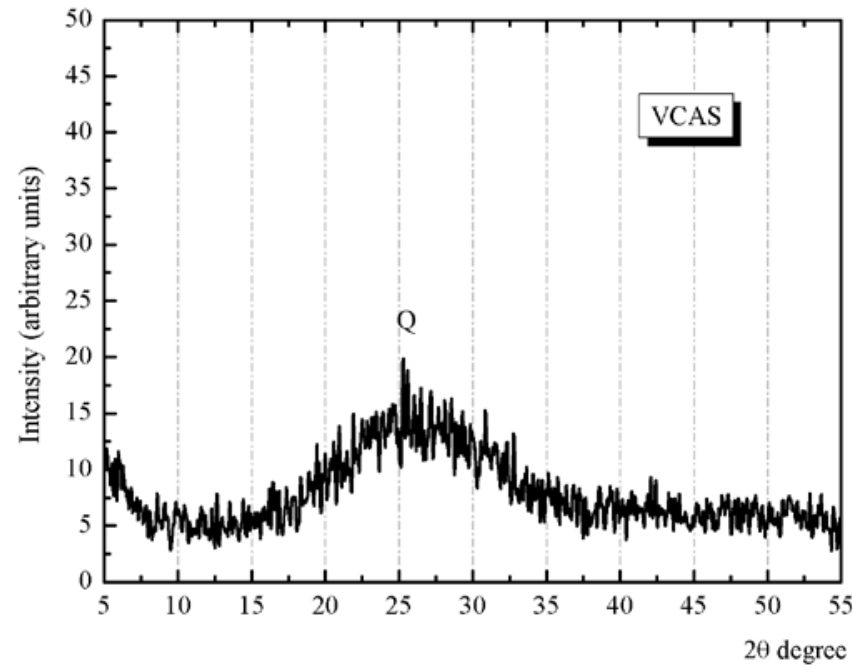

Figure 1. X-ray diffraction pattern of VCAS: Q - quartz (PDFcard \#461045). 
Other materials such as deionized water, Erlenmeyer flasks of $100 \mathrm{~mL}$ and plastic film were necessary for the analysis of pozzolanic reactivity using the $\mathrm{pH}$ and electrical conductivity method [19].

\subsection{Equipment}

Thermogravimetric analysis was carried out using a TGA 850 thermo-balance (Mettler Toledo). The tests were performed using $100 \mu \mathrm{L}$ aluminium crucibles, with a pinholed lid, using a nitrogen flow of 75 $\mathrm{mL} / \mathrm{min}$. Samples were heated in the temperature range of $35-600{ }^{\circ} \mathrm{C}$ at a $10^{\circ} \mathrm{C} / \mathrm{min}$ heating rate. Samples from pastes were obtained by grinding with acetone, filtering, and the resulting solid was heated in a laboratory oven at $60{ }^{\circ} \mathrm{C}$ for $30 \mathrm{~min}$. Powders were stored in Eppendorf safe-lock tubes until TGA tests were performed.

A shaking water bath JULABO - SW22 working in the temperature range $20-99.9^{\circ} \mathrm{C}$, a pH meter Crison micro pH 2001 and an electrical conductivimeter Crison micro CM 2201 were used for the determination of the pozzolanic reactivity by means of $\mathrm{pH}$ and electrical conductivity measurements according to the procedures described by Tashima et al. [19].

Mechanical strength tests of mortars were performed using a universal test machine following the procedures described in UNE-EN 196-1. The compressive strength value for each mixture was the average of six specimens.

The porosity of mortars was assessed on AutoPore IV 9500 porosimeter of Micrometrics Instrument Corporation with a range of pressures between 13.782 Pa and 227.4 MPa. Mortar samples were evaluated using mercury at a pressure up to $0.21 \mathrm{MPa}$ in the low pressure port, and at 227.4 $\mathrm{MPa}$ in the high pressure port.

\section{Results and discussion}

This section is divided into two parts in order to facilitate the analysis of the obtained data related to the pozzolanic reactivity of VCAS. The first part is related to the assessment of pozzolanic activity of VCAS 
based on calcium hydroxide/VCAS systems and the second part is related to Portland cement/VCAS systems.

\subsection{Studies on calcium hydroxide/VCAS systems}

\subsubsection{Thermogravimetric analysis studies}

The use of thermogravimetric analysis (TGA) on calcium hydroxide/pozzolan pastes is one of the most commonly used instrumental techniques to assess the pozzolanic reactivity of materials [20-21]. This technique is based on the $\mathrm{Ca}(\mathrm{OH})_{2}$ consumption by the pozzolanic reaction for different curing times: acidic oxides in pozzolan $\left(\mathrm{SiO}_{2}, \mathrm{Al}_{2} \mathrm{O}_{3}\right)$ react towards calcium hydroxide to form cementitious compounds (calcium silicate hydrates C-S-H, calcium aluminate hydrates C-A-H and calcium aluminosilicate hydrates C-A-S-H). For this purpose, the fixed calcium hydroxide can be expressed using the following equation [21]:

fixed $\mathrm{Ca}(\mathrm{OH})_{2}(\%)=\frac{\mathrm{CH}_{0}-\mathrm{CH}_{\mathrm{P}}}{\mathrm{CH}_{0}} * 100$

where $\mathrm{CH}_{\mathrm{o}}$ is the initial amount of calcium hydroxide in the mixture and $\mathrm{CH}_{\mathrm{p}}$ is the remaining amount of calcium hydroxide after a given curing age, which was calculated from the TG curve of the cured paste.

The amount of calcium hydroxide $\left(\mathrm{CH}_{\mathrm{p}}\right)$ remaining in the paste can be calculated using Equation 2 . It is well known that the mass loss in the thermogravimetric curve is associated with the dehydroxylation of calcium hydroxide according to Equation 3:

$\mathrm{CH}_{\mathrm{P}}=\frac{\mathrm{H}}{\mathrm{Mr}_{\mathrm{H}}} * \mathrm{Mr}_{\mathrm{CH}}$

where:

$\mathrm{H}$ is the mass loss associated with the dehydroxylation of calcium hydroxide; $\mathrm{Mr}_{\mathrm{H}}$ is the molecular mass of water and $\mathrm{Mr}_{\mathrm{CH}}$ is the molecular mass of calcium hydroxide.

$\mathrm{Ca}(\mathrm{OH})_{2} \rightarrow \mathrm{CaO}+\mathrm{H}_{2} \mathrm{O}$ 
In order to assess the pozzolanic reactivity of VCAS, pastes with three different calcium hydroxide/VCAS proportions (2:1; 1:1; $1: 2$ by mass) and with a constant water/binder ratio of 0.8 (where the binder is the sum of calcium hydroxide and VCAS) were cured at room temperature and tested after 3, 7, 14, 28 and 90 curing days.

Table 2 shows the fixed $\mathrm{Ca}(\mathrm{OH})_{2}$ for different curing times. The percentage of $\mathrm{Ca}(\mathrm{OH})_{2}$ consumption is increased with the curing time for all calcium hydroxide/VCAS proportions. It indicates that the pozzolanic reaction occurs not only for early, but also, for long curing times. After 90 days of curing, the obtained values for fixed $\mathrm{Ca}(\mathrm{OH})_{2}$ are $65.1,81.5$ and $92.9 \%$ for 2:1, 1:1, 1:2 calcium hydroxide/VCAS proportions, respectively. Comparing these values with fixed $\mathrm{Ca}(\mathrm{OH})_{2}$ after 3 days of curing, a very significant increment for all proportions (2:1, 1:1 and 1:2) are yielded: 380, 295 and 242\%, respectively.

Table 2. Fixed $\mathrm{Ca}(\mathrm{OH})_{2}$ in percentage for different calcium hydroxide/VCAS proportions and for several curing times.

\begin{tabular}{cccccc}
\hline & \multicolumn{5}{c}{ Fixed $\mathrm{Ca}(\mathrm{OH})_{2}(\%)$} \\
\cline { 2 - 6 } & 3 days & 7 days & 14 days & 28 days & 90 days \\
\hline $2: 1$ & 17.1 & 24.1 & 41.7 & 53.2 & 65.1 \\
$1: 1$ & 27.6 & 41.5 & 51.8 & 64.1 & 81.5 \\
$1: 2$ & 38.3 & 53.9 & 66.5 & 83.5 & 92.9 \\
\hline
\end{tabular}

In order to compare the obtained data with well-known pozzolanic materials reported in the literature, the fixed $\mathrm{Ca}(\mathrm{OH})_{2}$ for mixes with different VCAS content (\%VCAS) after 28 days curing was determined adjusting experimental data to a linear fitting curve (Fixed $\mathrm{Ca}(\mathrm{OH})_{2}=22.37+0.89 * \% \mathrm{VCAS}, \mathrm{R}^{2}=0.95$ ). Extrapolating the obtained data from fitting curve, it is possible to compare the pozzolanic reactivity of VCAS with others pozzolans. According to the fitting curve, for $30 \%$ of VCAS, the fixed $\mathrm{Ca}(\mathrm{OH})_{2}$ after 28 days of curing is about $49 \%$, similar to the experimental data obtained for $33 \%$ of VCAS (2:1 calcium hydroxide/VCAS) that yielded about 53\% of fixed $\mathrm{Ca}(\mathrm{OH})_{2}$. 
In a specific study about calcium hydroxide/fly ash pastes with $30 \%$ of fly ash, the fixed $\mathrm{Ca}(\mathrm{OH})_{2}$ was about $26 \%$ after 28 days of curing [22]. As can be observed, fly ash is a material with lower pozzolanic reactivity than VCAS after 28 days of curing.

Comparing the reactivity of VCAS with high reactive pozzolans such as FC3R and metakaolin (high reactive $\mathrm{Al}_{2} \mathrm{O}_{3}-\mathrm{SiO}_{2}$ based pozzolanic materials) for the same proportion (30\%), the fixed $\mathrm{Ca}(\mathrm{OH})_{2}$ after 28 days of curing for these pozzolans are higher than 95\% [21]. Despite the relatively high percentage of calcium in its composition, VCAS is a SCM with interesting pozzolanic activity.

The amount of $\mathrm{Ca}(\mathrm{OH})_{2}$ combined per gram of VCAS is also given in Table 3. This ratio $\Psi$, $\mathrm{gCa}(\mathrm{OH})_{2} / \mathrm{gVCAS}$, was higher for the 2:1 system due to the availability of calcium hydroxide being the highest: thus, for 90 days of curing, this ratio was 1.30 . When the calcium hydroxide is nearly $100 \%$ reacted $\left(1: 2 \mathrm{Ca}(\mathrm{OH})_{2} / \mathrm{VCAS}\right.$ ratio, 90 days), the amount of $\mathrm{Ca}(\mathrm{OH})_{2}$ fixed per gram of VCAS is only 0.46. This means that the $\mathrm{Ca} /(\mathrm{Al}+\mathrm{Si})$ ratio in the pozzolanic reaction products will be different depending on the quantity of $\mathrm{Ca}(\mathrm{OH})_{2}$ available in the medium.

Table 3. Relative mass of $\mathrm{Ca}(\mathrm{OH})_{2}$ combined per gram of VCAS $\left(\mathrm{gCa}(\mathrm{OH})_{2} / \mathrm{gVCAS}, \Psi\right)$ in calcium hydroxide/VCAS pastes.

\begin{tabular}{cccccc}
\hline & \multicolumn{5}{c}{ Relative mass of $\mathrm{Ca}(\mathrm{OH})_{2}-\Psi$} \\
\cline { 2 - 6 } & 3 days & 7 days & 14 days & 28 days & 90 days \\
\hline $2: 1$ & 0.34 & 0.48 & 0.83 & 1.06 & 1.30 \\
$1: 1$ & 0.28 & 0.41 & 0.52 & 0.64 & 0.81 \\
$1: 2$ & 0.19 & 0.27 & 0.33 & 0.42 & 0.46 \\
\hline
\end{tabular}

Hence, according to the analysis performed, VCAS can be considered as a pozzolanic material with a higher reactivity than fly ash, but with lower reactivity than is found for highly reactive pozzolans such as metakaolin and FC3R. 
Figure 2 shows the DTG curves of calcium hydroxide/VCAS pastes cured for 28 days. The main hydrated product formed due to the pozzolanic reaction is the C-S-H gel that is represented by the peak centred at $120^{\circ} \mathrm{C}$ in the derivative curve. The peak centred at $210^{\circ} \mathrm{C}$ is related to the decomposition of calcium aluminate hydrates and calcium aluminosilicate hydrates formed due to the presence of reactive $\mathrm{Al}_{2} \mathrm{O}_{3}$ in the composition of VCAS. The peak centred at $550{ }^{\circ} \mathrm{C}$ is related to the dehydroxylation of non-reacted $\mathrm{Ca}(\mathrm{OH})_{2}$ in the pastes.

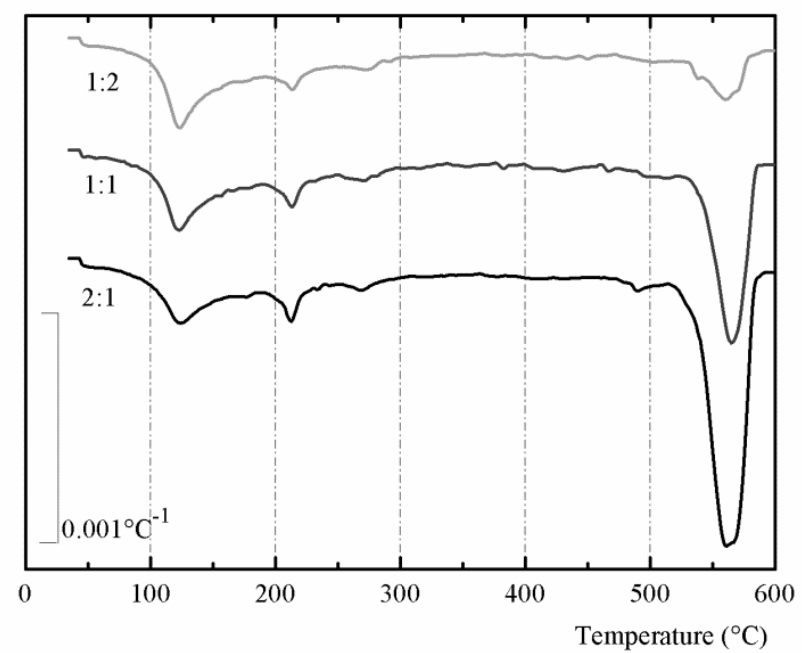

Figure 2. DTG curves for calcium hydroxide/VCAS pastes with different proportions (2:1, 1:1, 1:2), cured for 28 days.

\subsection{2. $\mathrm{pH}$ and electrical conductivity studies on pastes}

The pozzolanic reaction was also monitored by means of $\mathrm{pH}$ and electrical conductivity measurements according to the method proposed by Tashima et al. [19]. According to this method, different $\mathrm{Ca}(\mathrm{OH})_{2}$ :pozzolan proportions $(2: 8 ; 2.5: 7.5 ; 3: 7 ; 3.5: 6.5 ; 4: 6 ; 4.5: 5.5)$ should be tested during 7 days at 40,50 and $60^{\circ} \mathrm{C}$.

In this method, two main contributions to the $\mathrm{pH}$ and electrical conductivity of the liquid medium may be considered: on the one hand, the calcium and hydroxyl ions from the partial solubilization of calcium hydroxide (remember that this salt is not very soluble in water); and, on the other hand, the ions released by the partial dissolution of pozzolan (usually the quantity of ions released is very low). During the reaction, the main process that affects the presence of ions in the aqueous medium is the pozzolanic 
reaction, reducing the concentration of calcium and hydroxyl ions. If solid $\mathrm{Ca}(\mathrm{OH})_{2}$ is still present in the suspension, it dissolves in order to saturate the solution; if not, the concentration of calcium and hydroxyl ions decreases, and then there is a corresponding decrease in the $\mathrm{pH}$ and electrical conductivity. The results obtained are expressed as loss of conductivity $\left(\operatorname{Lc}(\%)_{t}\right)$ versus time (hours). It is important to state that just $\left[\mathrm{OH}^{-}\right]$values were used as the confirming parameter of the pozzolanic reaction since variations in the electrical conductivity values are easily detected [19]. Hence, the $\operatorname{Lc}(\%)_{\mathrm{t}}$ values are obtained through the following Equations 4 and 5:

$L c(\%)_{\mathrm{t}}=\frac{C_{0}-C_{t, c}}{C_{0}} * 100$

$C_{t, c}=C_{t}-C_{t, p o z}$

where:

$\mathrm{C}_{\mathrm{o}}$ is the electrical conductivity of the calcium hydroxide suspension before addition of the pozzolan;

$\mathrm{C}_{\mathrm{t}}$ is the electrical conductivity measured after t hours of reaction;

$\mathrm{C}_{\mathrm{t}, \mathrm{poz}}$ is the electrical conductivity released by the pozzolan after $\mathrm{t}$ hours of reaction;

$\mathrm{C}_{\mathrm{t}, \mathrm{c}}$ is the electrical conductivity corrected by the release of ions from the pozzolan after $\mathrm{t}$ hours of reaction.

Suspensions with an $\mathrm{Lc}(\%)$ value above $30 \%$ indicate the unsaturation of the suspension and, in this case, the time required for getting calcium hydroxide unsaturation in the suspension $\left(\mathrm{t}_{\mathrm{uns}}\right)$ was calculated based on the $\operatorname{Lc}(\%)$ for all testing temperatures.

Figure 3 depicts the $\mathrm{Lc}(\%)$ values for the different proportions of $\mathrm{Ca}(\mathrm{OH})_{2}: \mathrm{VCAS}$ tested at $40{ }^{\circ} \mathrm{C}$ during 7 days. It can be noted that only the proportion 2:8 was able to become unsaturated after 7 days of the test (the $\mathrm{t}_{\mathrm{uns}}$ value for $40^{\circ} \mathrm{C}$ was 120 hours). For all other proportions, the $\mathrm{Lc}(\%)$ is approximately constant during the testing period. This behaviour can be explained due to the high amount of $\mathrm{CaO}$ (about 23\%) in the VCAS composition, a fact that reduces the consumption of calcium hydroxide by the pozzolan. 


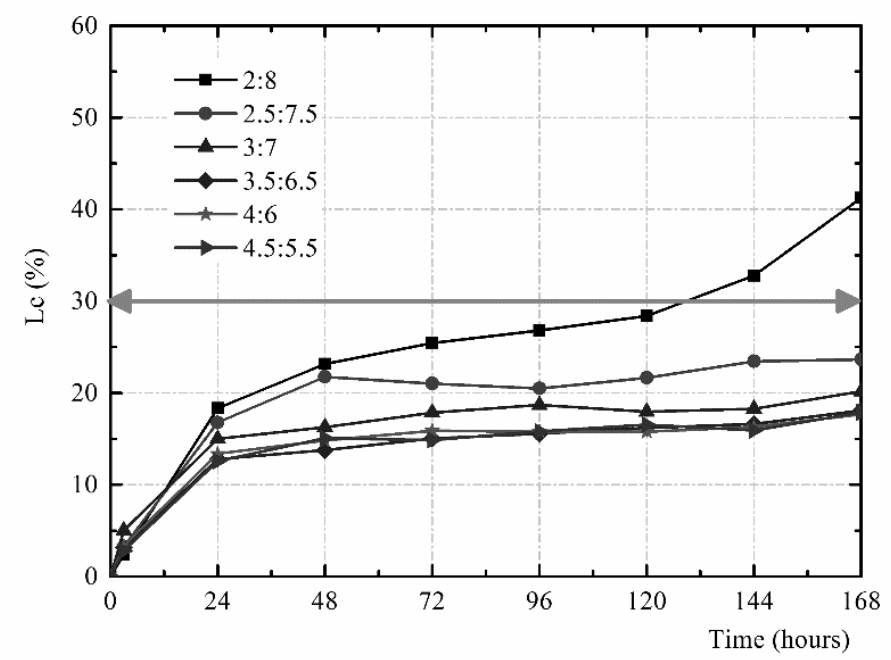

Figure 3. Loss of electrical conductivity for $\mathrm{Ca}(\mathrm{OH})_{2}: \mathrm{VCAS}$ suspensions at $40{ }^{\circ} \mathrm{C}$, during 7 days.

Comparing the reactivity of VCAS with other pozzolanic materials, in the Figure 4 is depicted the loss of electrical conductivity for $\mathrm{Ca}(\mathrm{OH})_{2}$ :pozzolan suspensions of both rice husk ash and densified silica fume for two different proportions: 2:8 and 2.5:7.5. The reactivity of siliceous pozzolans (high and low densified silica fume, DSF-H and DSF-L; amorphous and crystalline rice husk ash, RHA-A and RHA-C) was previously reported [19]. The amorphous rice husk ash (RHA-A) and low densified silica fume (DSF-L) are high reactive pozzolans yielding the unsaturation for both suspensions (Figure 4a and Figure 4b). High densified silica fume (DSF-H) and VCAS are able to unsaturate only the suspension 2:8, while the crystalline rice husk ash (RHA-C) was not able to unsaturate any suspension, indicating its low pozzolanic reactivity. Hence, VCAS present a pozzolanic behaviour between DSF-H and RHA-C.
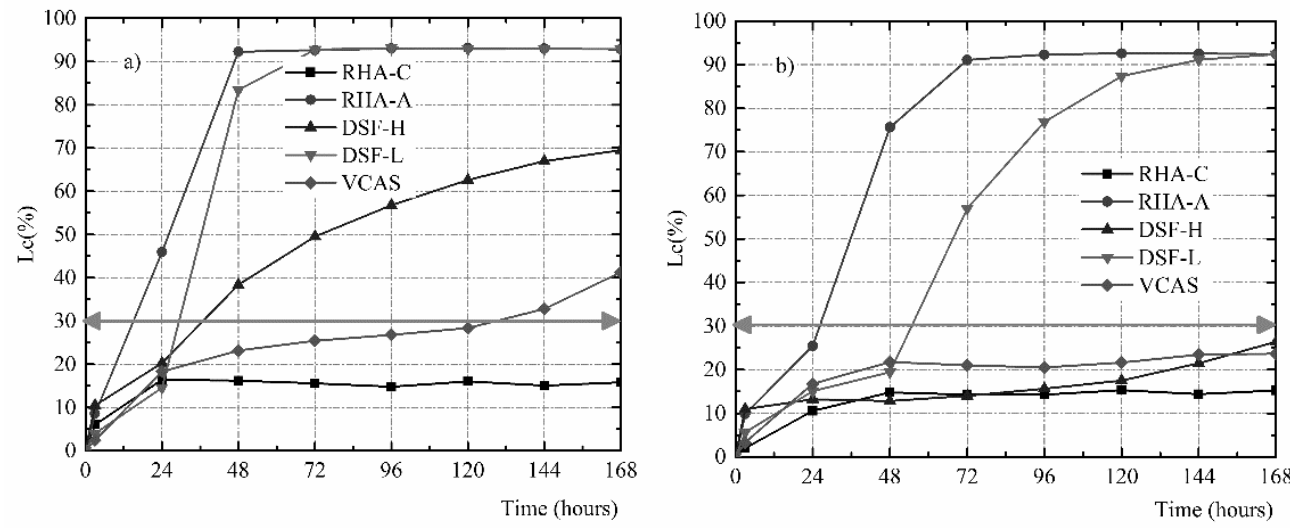

Figure 4. Comparative analysis of loss of electrical conductivity: a) 2:8 suspensions; b) 2.5:7.5 suspensions. 
In order to study the influence of temperature on the pozzolanic reaction, the same test was performed at 50 and $60^{\circ} \mathrm{C}$ for VCAS, and the loss of conductivity versus time is depicted in Figure 5a and Figure 5b, respectively. The increment on the testing temperature reduces the unsaturation time for suspension 2:8 ( $\mathrm{t}_{\mathrm{uns}}$ values were 93 and 88 hours for 50 and $60^{\circ} \mathrm{C}$, respectively). However, any more suspension was unsaturated for these testing temperatures.
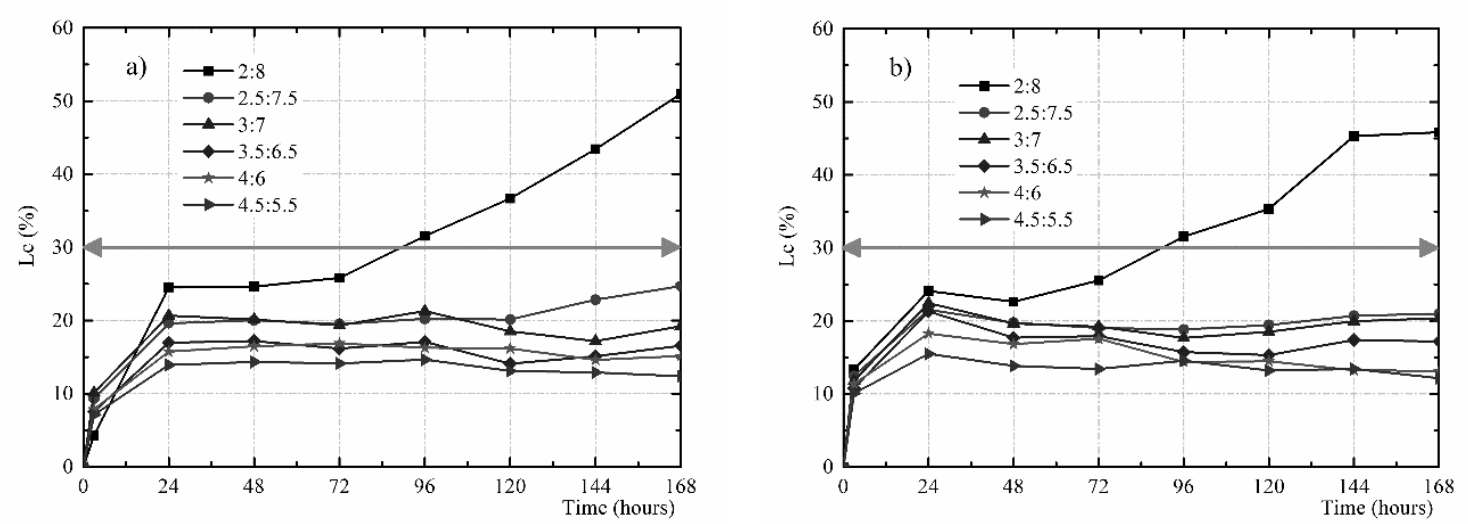

Figure 5. Loss of electrical conductivity for $\mathrm{Ca}(\mathrm{OH})_{2}$ :VCAS suspensions during 7 days at: a) $50{ }^{\circ} \mathrm{C}$; b) 60 ${ }^{\circ} \mathrm{C}$.

Hence, based on the results obtained of $\mathrm{Lc}(\%)$ values for suspensions tested at 40,50 and $60{ }^{\circ} \mathrm{C}$ and using the criteria for the classification of pozzolanic materials proposed by Tashima et al. [19] that is based on the unsaturation of $\mathrm{Ca}(\mathrm{OH})_{2}$ :pozzolan suspensions, VCAS should be considered a pozzolanic material with low reactivity, similar to DSF-H and RHA-C.

\subsection{Portland cement/VCAS systems}

\subsubsection{Thermogravimetric analysis studies}

The pozzolanic activity of VCAS in Portland cement system was assessed for 28 days curing time in pastes prepared with a water/binder ratio of 0.5 and with different percentages of VCAS partially replacing OPC (10, 20 and 30\%, by mass).

The fixed $\mathrm{Ca}(\mathrm{OH})_{2}$ in Portland cement/VCAS systems is calculated according to Eq. 6, which takes into account the percentage of pozzolan replacing Portland cement: 
fixed $\mathrm{Ca}(\mathrm{OH})_{2}(\%)=\frac{\left(\mathrm{CH}_{\mathrm{C}} \times \mathrm{C}_{\%}\right)-\mathrm{CH}_{\mathrm{P}}}{\left(\mathrm{CH}_{\mathrm{C}} \times \mathrm{C}_{\%}\right)} * 100$

where:

$\mathrm{CH}_{\mathrm{C}}$ is the amount of calcium hydroxide in the control paste (only cement) for a given curing age;

$\mathrm{CH}_{\mathrm{P}}$ is the amount of calcium hydroxide in the pozzolan blended paste for the same curing age as the control paste;

$\mathrm{C}_{\%}$ is the proportion of OPC in the blended paste $(0.9,0.8$ and 0.7 for 10,20 and $30 \%$ replacing percentages, respectively).

In Table 4 are presented all data related to the thermogravimetric analysis: (percentages of water released due to calcium hydroxide decomposition) and $\mathrm{C} \%$ and fixed $\mathrm{Ca}(\mathrm{OH})_{2}$ after 28 days of curing. Using Eq. 6 to calculate the fixed $\mathrm{Ca}(\mathrm{OH})_{2}$ for pastes cured for 28 days, it can be observed that Portland cement pastes with 10, 20 and 30\% of VCAS fixed 5.9\%, 18.2\% and 13.9\%, respectively.

Table 4. Amount of calcium hydroxide (expressed as percentage of water released in thermogravimetric analysis) in both control and VCAS blended pastes, proportion of OPC (C\% in VCAS pastes) and percentage of fixed $\mathrm{Ca}(\mathrm{OH})_{2}$ after 28 days of curing.

\begin{tabular}{cccc}
\hline & $\mathrm{CH}$ & $\mathrm{C} \%$ & Fixed $\mathrm{Ca}(\mathrm{OH})_{2}(\%)$ \\
\hline control & 3.63 & - & - \\
$10 \%$ VCAS & 3.08 & 0.90 & 5.9 \\
$20 \%$ VCAS & 2.38 & 0.80 & 18.2 \\
$30 \%$ VCAS & 2.19 & 0.70 & 13.9 \\
\hline
\end{tabular}

Comparing the results to the literature, Antiohos et al. [23] obtained a fixed $\mathrm{Ca}(\mathrm{OH})_{2}$ in the range 5-7\% for replacement levels of $20 \%$ of both high and low calcium fly ashes. Weerdt et al. [24] presented TGA study that allows to calculate the fixed $\mathrm{Ca}(\mathrm{OH})_{2}$ for fly ash. In this case, a negative value $(-3.3 \%)$ of fixed $\mathrm{Ca}(\mathrm{OH})_{2}$ after 28 days of curing was obtained and, after 90 days, this value is increased to $14.9 \%$. 
Figure 6 shows the DTG curves for Portland cement/VCAS pastes after 28 curing days. Similar to the results obtained for calcium hydroxide/VCAS pastes, the main process observed in the DTG curves is the dehydration of C-S-H gel, which is represented by a peak in the range $100-180{ }^{\circ} \mathrm{C}$. In this case, the presence of a second peak overlapped with the C-S-H gel peak can be observed. This may be associated with the dehydration of ettringite [25]. The mass loss in the range $35-250{ }^{\circ} \mathrm{C}$ was very similar for all the studied samples. Although the pozzolanic contribution of VCAS is not too high, the amount of hydrates found for VCAS-containing pastes was very similar to that found in the control paste: this suggests that a hydraulic contribution from VCAS took place in the hydration of the VCAS/OPC mix.

For the OPC paste, a peak centred at $210^{\circ} \mathrm{C}$ is observed. This may be associated with the dehydration of calcium aluminate hydrates and calcium aluminosilicate hydrates formed during Portland cement hydration. For Portland cement/VCAS pastes, the peak centred at $210{ }^{\circ} \mathrm{C}$ was slightly greater with respect to the control paste, which is attributed to the pozzolanic and hydraulic reactions.

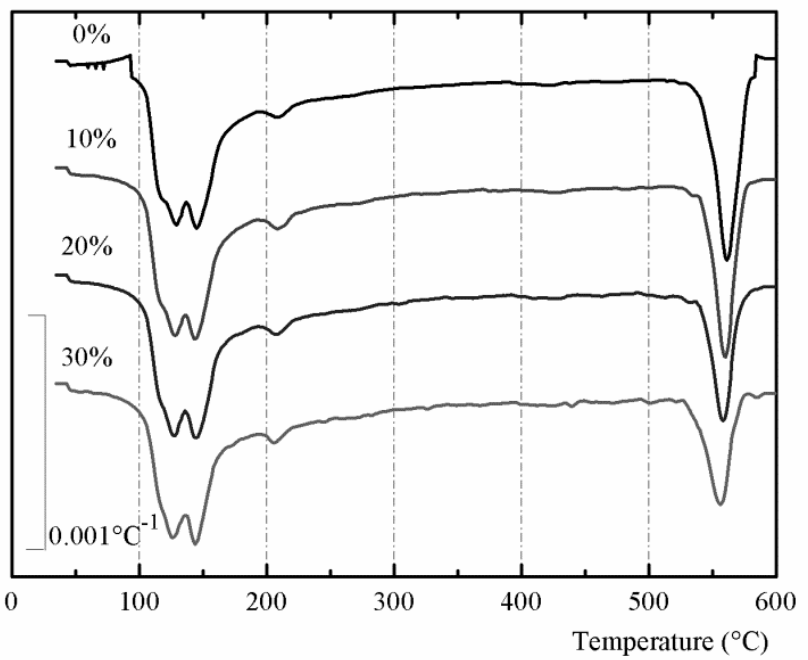

Figure 6. DTG curves for Portland cement/VCAS pastes with different replacements (0, 10, 20 and 30\%) after 28 days curing time.

\subsubsection{Compressive strength of mortars}

The behaviour of VCAS replacing OPC in blended mortars was also evaluated. The data obtained for the compressive strength of blended mortars (0, 10, 20 and 30\% of VCAS) cured at room temperature after

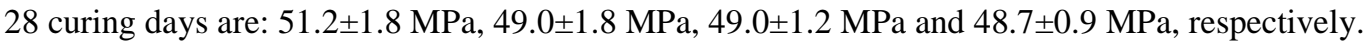


As can be observed, all the blended mortars assessed present about 50 MPa for compressive strength, a value slightly lower than that obtained for the control mortar. These results are very interesting since the blended mortars presented a significant reduction in the Portland cement consumption (up to 30\%, by mass) and, consequently, a reduction in the greenhouse gas emissions related to this new blended cement. From the mechanical strength point of view, the results obtained are also very significant and they can be expressed using the following Eq. 7:

$\mathrm{CSI}=\frac{\mathrm{R}_{\mathrm{poz}}}{\mathrm{R}_{\mathrm{c}}}$

where:

CSI is the compressive strength index;

$\mathrm{R}_{\mathrm{poz}}$ is the compressive strength for the blended mortar.

$R_{c}$ is the compressive strength for the control mortar;

For all the assessed mortars, the obtained CSI is about 0.95 , independently of the percentage of VCAS: 0.96, 0.96 and 0.95 for $10 \%, 20 \%$ and $30 \%$ of VCAS, respectively. In the literature, on the one hand, it can be found that a highly reactive pozzolanic material such as silica fume presented a CSI similar to or even slightly higher than unity. For that case, the amount of silica fume replacing OPC was in the range of 5-15\%, by mass [26]. For the VCAS blended mortars studied here, the amount of VCAS replacing OPC can reach $30 \%$ without a significant reduction in the compressive strength value, indicating a good mechanical contribution from this supplementary cementitious material.

On the other hand, comparing VCAS with fly ash, a pozzolanic material that can be used to replace OPC in high percentages, it can be observed that fly ash blended mortars present a significant reduction in the CSI, from 0.73-0.90, depending on the amount of fly ash, 10-25\% [27]. Nevertheless, VCAS blended mortars do not present any significant reduction for the compressive strength index, even using a high percentage of VCAS replacing OPC. 
In terms of cementing efficiency (k-factor), two approaches are made based respectively on Bolomey's and Abrams' models. The k-factor values have been calculated for VCAS in the $10-30 \%$ replacing range for mortars. Rao [27] analyzed the behaviour of compressive strength in Portland cement mortars, and he proposed empirical model expressions to predict the compressive strength dependence in terms of the water/cement (w/c) ratio. The first expression proposed by Rao [28] was as shown in Eq. 8:

$\sigma=a\left[\frac{1}{\frac{w}{c}}+b\right]$

where $\sigma$ is the compressive strength, a and b are two constants (which can be calculated from compressive strength values for mortars with different w/c ratios). Constants were calculated for the OPC used in this research: $a=23.286 \mathrm{MPa}$ and $\mathrm{b}=0.2010 \mathrm{MPa}$. For VCAS blended mortars, and taking into account the cementing efficiency factor (k) for the SCM used, Eq. 8 is transformed into Eq. 9 as follows:

$\sigma=a\left[\frac{1}{\frac{w}{c+k p}}+b\right]$

where $\mathrm{p}$ is the amount of VCAS. From Eq. 9, k can be calculated as follows (Eq. 10):

$k=\frac{\left[\frac{\sigma}{a}-b\right] w-c}{p}$

The calculated k-values for VCAS were $0.51,0.75$ and 0.82 for 10, 20 and 30\% replacement percentages, respectively. The most interesting fact is the increase of k-values with increase of the replacing percentage, which suggests that the reduction in the amount of Portland cement does not affect the reactivity of VCAS, probably due to its hydraulic contribution and moreover its pozzolanic role. These values obtained for mortars cured for 28 days were significantly higher than those found for fly ash, and slightly lower than those found for silica fume. Antiohos et al. [23] obtained k-values of 0.88 and 0.78 for fly ash replacement of 20 and 30\%, respectively. Papadakis et al. [29] obtained for 28 days of curing k-values lower than 0.3 for natural pozzolans and 1.1 for a high calcium fly ash (14.8\% CaO). The k-values were also calculated using the second expression proposed by Rao [28] (Eq. 11): 
$\sigma=\alpha\left(\frac{w}{c}\right)^{-\beta}$

For OPC replaced mortars, this expression can be rewritten as follows (Eq. 12):

$\sigma=\alpha\left(\frac{w}{c+k p}\right)^{-\beta}$

where $\alpha$ and $\beta$ are constants, which can be calculated in the same way as "a" and "b" for the first model. In our case, $\alpha=27.089 \mathrm{MPa}$ and $\beta=0.9193$.

The k-values can be calculated from Eq. 11 according to Eq. 13:

$k=\frac{1}{p}\left[\frac{w}{10 \frac{\log \alpha-\log \sigma}{\beta}}-c\right]$

For this model, the k-values obtained were $0.52,0.76$ and 0.82 for 10,20 and $30 \%$ replacing percentages, respectively. These values follow the same trend as before and are very similar.

\subsubsection{Porosity studies}

The effect of VCAS on the OPC matrix was studied by mercury intrusion porosimetry (MIP). The control OPC mortar (0\% replacement) and mortar containing 30\% VCAS were selected for these studies.

Figure 7 shows the pore distributions obtained from MIP tests on mortar samples cured for 28 days. The relative content in gel pores $(<10 \mathrm{~nm})$ was very similar in both mortars, suggesting that in the studied conditions, the pore refinement due to the reactivity of VCAS does not modify the gel pore structure. However, the presence of VCAS reduced the content of large capillary pores $(100-1000 \mathrm{~nm})$ and increased the medium capillary pores $(10-100 \mathrm{~nm})$, suggesting that the reaction products due to VCAS evolution in the presence of OPC modify notably the size of capillary pores. This behaviour could have interesting advantages in terms of durability (permeability properties). Additionally, the total porosity measured for 30\%-VCAS mortar (9.66\%) was significantly lower than that observed for OPC mortar (12.20\%). This means that, although the relative content in gel pores did not differ between the two mortars, the absolute volume percentage for this type of pores is different when comparing the two 
mortars. Thus, the behaviour related to shrinkage and creep will be more favorable for systems containing VCAS.

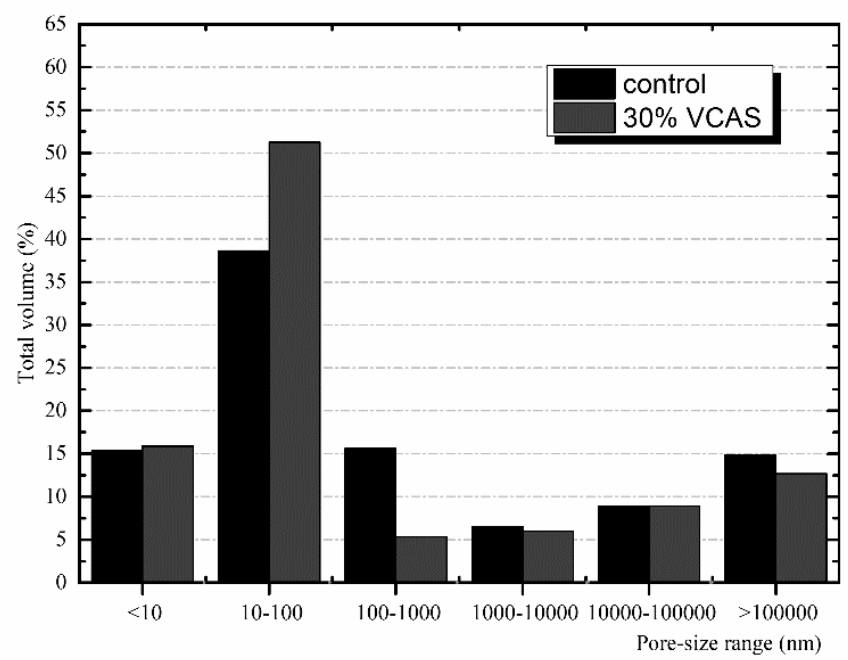

Figure 7. Porosity distribution for OPC and 30\% VCAS mortars.

\section{Conclusions}

A waste material from the glass fibre industry, by means of a further fusion process, has been transformed into an supplementary cementitious material (SCM) for use in OPC blends. Different techniques were used in order to assess the reactivity of VCAS. Thermogravimetric analysis of calcium hydroxide/VCAS pastes demonstrated that VCAS possesses significant pozzolanic properties, and that, depending on the mix proportion, the amount of fixed calcium hydroxide per gram of VCAS is increased with curing time and that this value can vary in the range $0.46-1.30$ after 90 days curing time.

From $\mathrm{pH}$ and electrical conductivity measurements, it can be observed that the pozzolanic reaction rate of VCAS is slow. Even when the test was performed at $60^{\circ} \mathrm{C}$, only the 2:8 suspension reached unsaturation. This fact can be explained by the presence of $\mathrm{CaO}$ in the chemical composition of VCAS, which reduces the requirement for calcium hydroxide. This behaviour demonstrated that VCAS could present a hydraulic contribution when mixed with OPC. 
Thermogravimetric analysis of Portland cement/VCAS pastes showed that hydrated products formed in the reaction are mainly C-S-H gel and calcium aluminosilicate hydrates. The reactivity of VCAS produced a very limited pozzolanic contribution (5-18\% of fixed calcium hydroxide), while its hydraulic activity yielded cementing products.

Finally, the use of VCAS in the production of blended mortars presented very interesting results in terms of compressive strength. The replacement of OPC by VCAS in the range of 10-30\% produced a similar compressive strength to the control mortar after 28 curing days. The cementing efficiency (k-value) was calculated for VCAS in OPC blended mortars using two models. Similar k-values were obtained in both models. The k-values found were in the range of 0.51-0.82, suggesting that VCAS presented a reactivity higher than is usually found for fly ashes, and lower than that found for silica fume. The increase of the kvalue for VCAS in the highest replacement percentage (30\%) becomes very interesting because the reduction in portlandite content from the hydration of OPC does not significantly affect the cementing role of VCAS.

The effect of VCAS in OPC systems is positive in microstructural terms, because the total porosity and the large capillary pores were decreased compared to the behaviour of plain OPC.

\section{Acknowledgements}

The authors would like to thank Vitrominerals Company for supplying VCAS samples.

The authors are grateful to the Spanish Ministry of Science and Innovation for supporting this study through Project GEOCEDEM BIA 2011-26947, and to FEDER funding.

\section{References}

[1] Cement Sustainability Initiative. Cement industry energy and $\mathrm{CO}_{2}$ performance, getting the numbers right. World Business Council for Sustainable Development, 2009.

[2] L. Barcelo, J. Kline, G. Walenta, E. Gartner, Cement and carbón emissions, Mater Struct. 47 (2014) 1055-1065.

[3] E.R. Grist, K.A. Paine, A. Heath, J. Norman, H. Pinder, Compressive strength development of binary and ternary lime-pozzolan mortars, Mater. Des. 52 (2013) 514-523. 
[4] A. Moropoulou, A. Bakolas, E. Aggelakopoulou, Evaluation of pozzolanic activity of natural and artificial pozzolans by thermal analysis., Thermochim. Acta. 420 (2004) 135-140.

[5] L.P. Esteves, On the hydration of water-entrained cement-silica systems: combined SEM, XRD and thermal analysis in cement pastes, Thermochim. Acta. 518 (2011) 27-35.

[6] A.M. Rashad, Metakaolin as cementitious material: history, scours, production and composition - a comprehensive overview, Constr. Build. Mater. 41 (2013) 303-318.

[7] H.K. Venkatanarayanan, P.R. Rangaraju, Effect of grinding of low-carbon rice husk ash on the microstructure and performance properties of blended cement concrete, Cem. Concr. Compos. 55 (2015) 348-363.

[8] V. Tydlitát, J. Zákoutský, P. Volfová, R. Cěrný, Hydration heat development in blended cements containing fine-ground ceramics, Thermochim. Acta. 543 (2013) 125-129.

[9] K. Al-Jabri, M. Baawain, R. Taha, Z.S. Al-Kamayani, K. Al-Shamsi, A. Ishtieh, Potential use of FCC spent catalyst as partial replacement of cemento r sand in cement mortars, Constr. Build. Mater. 39 (2013) 77-81.[10] M. Frías, E. Villar, H. Savastano, Brazilian sugar cane bagasse ashes from the cogeneration industry as active pozzolans for cement manufacture, Cem. Concr. Compos. 33 (2011) 490-496.

[11] S. Rukzon, P. Chindaprasirt, Utilization of bagasse ash in high-strength concrete, Mater. Des. 34 (2012) 45-50.

[12] K. Montakarntiwong, N. Chusilp, W. Tangchirapat, C. Jaturapitakkul, Strength and heat evolution of concretes containing bagasse ash from thermal power plants in sugar industry, Mater. Des. 49 (2013) 414420.

[13] R.T. Hemmings, R.D. Nelson, P.L. Graves, B.J. Cornelius, White pozzolan composition and blended cements containing same, US Patent US6776838 (2004).

[14] A. Hossain, S.A. Shirazi, Properties of concrete containing vitreous calcium aluminosilicate pozzolan, J. Transp. Res. 2070 (2008) 32-38.

[15] N. Neithalath, J. Persun, A. Hossain, Hydration in high-performance cementitious systems containing vitreous calcium aluminosilicate or silica fume, Cem. Concr. Res. 39 (2009) 473-481.

[16] M.M. Tashima, L. Soriano, M.V. Borrachero, J. Monzó, C.R. Cheeseman, J. Payá, Alkali activation of vitreous calcium aluminosilicate derived from glass fiber waste, J. Sustain. Cem.-based Mater. 1 (2012) 83-93. 
[17] M.M. Tashima, L. Soriano, M.V. Borrachero, J. Monzó, J. Payá, Effect of curing time on microstructure and mechanical strength development of alkali activated binders based on vitreous calcium aluminosilicate (VCAS), Bull. Mater. Sci. 36 (2013) 245-249.

[18] M.M. Tashima, L. Soriano, J. Monzó, M.V. Borrachero, J. Payá, Novel geopolymeric material cured at room temperature, Adv. Appl. Ceram. 112 (2013) 179-183.

[19] M.M. Tashima, L. Soriano, J. Monzó, M.V. Borrachero, J.L. Akasaki, J. Payá, New method to assess the pozzolanic reactivity of mineral admixtures by means of $\mathrm{pH}$ and electrical conductivity measurements in lime:pozzolan suspensions, Mater. Constr. 64 (2014) 1-12.

[20] G.C. Cordeiro, C.P. Sales, Pozzolanic activity of elephant grass ash and its influence on the mechanical properties of concrete, Cem. Concr. Compos. 55 (2015) 331-336.

[21] J. Payá, J. Monzó, M.V. Borrachero, S. Velásquez, M. Bonilla, Determination of pozzolanic activity of fluid catalytic cracking residue: Thermogravimetric analysis studies on FC3R-lime pastes, Cem. Concr. Res. 33 (2003) 1085-1091.

[22] F. Amahjour, Estudio de la reactividad de las puzolanas artificiales: cenizas volantes y humo de sílice, y su reutilización en ingeniería civil. [PhD thesis]. Universitat Politècnica de València (2000), in Spanish.

[23] S. Antiohos, K. Maganari, S. Tsimas, Evaluation of blends of high and low calcium fly ashes for use as supplementary cementing materials, Cem. Concr. Compos. 27 (2005) 349-356.

[24] K. De Weerdt, M. Ben Haha, G. Le Saout, K.O. Kjellesen, H. Justnes, B. Lothenbach, Hydration mechanisms of ternary Portland cements containing limestone powder and fly ash, Cem. Concr. Res. 41 (2011) 279-291.

[25] P. Thongsanitgarn, W. Wongkeo, A. Chaipanich, Hydration and compressive strength of blended cement containing fly ash and limestone as cement replacement, J. Mater. Civ. Eng. 26 (2014) 1-5.[26] Y. Senhadji, G. Escadeillas, M. Mouli, H. Khelafi, Benosman, Influence of natural pozzolan, silica fume and limestone fine on strength, acid resistance and microstructure of mortar, Powder Technol. 254 (2014) 314-323.

[27] Y. Kocak, S. Nas, The effect of using fly ash on the strength and hydration characteristics of blended cements, Constr. Build. Mater. 73 (2014) 25-32.

[28] G.A. Rao, Generalization of Abram’s law for cement mortars, Cem. Concr. Res. 31 (2001) 495-502. 
[29] V.G. Papadakis, S. Antiohos, S. Tsimas, Supplementary cementing materials in concrete Part II: A fundamental estimation of the efficiency factor, Cem. Concr. Res. 32 (2002) 1533-1538. 